\title{
Antimonumentos entre a Escultura e os Quadrinhos
}

\section{Resumo}

Este texto aborda uma intervenção artística ocorrida dentro de um projeto que alia as linguagens da escultura e das histórias em quadrinhos. São explicitados alguns referenciais poéticos do trabalho (Gustavo Nakle, Honoré Daumier e Angelo Agostini) e também questões relativas a seus processos de criação e recepção, num diálogo com o humor e os conceitos de ruído comunicacional e de antimonumento.

Palavras-chave: Escultura; história em quadrinhos; antimonumento; arte pública.

\section{Anti-Monuments between Sculpture and Comics}

\begin{abstract}
This text emphasizes an artistic intervention occurred inside a project which allies sculpture and comics' languages. Some of its poetic references (Gustavo Nakle, Honoré Daumier and Angelo Agostini) and questions about its processes of creation and reception are also explicated, on a dialog with humor and with the concepts of communicational noise and anti-monument.
\end{abstract}

Key words: Sculpture; comics; anti-monument; public art.

\section{O projeto A...A...A...}

São abordadas aqui questões sobre os processos de criação e recepção de uma intervenção artística que fez parte de uma pesquisa em artes visuais voltada a fusões entre as linguagens da escultura e das histórias em quadrinhos. Como desdobramento dessas relações, parti da possibilidade de um diálogo expressivo com duas letras " $A$ " presentes nos arredores da Casa do Estudante da Universidade Federal de Santa Maria - estruturas de ferro outrora pertencentes a um balanço infantil.

O trabalho consistiu na disposição temporária de um "monumento" de papel que homenageava uma situação de desconforto de um personagem fictício, o ataque de espirros que teria acometido um aristocrata estrangeiro ao visitar o lugar. O intuito dessa experiência foi aproximar esta pesquisa poética a um diálogo com o conceito de antimonumento, promovendo uma paródia de determinadas situações e procedimentos comuns em nossa sociedade. 
Este projeto começou a ser desenvolvido a partir de uma proposta acadêmica de exposição ${ }^{1}$, como trabalho pensado para um lugar institucional, apesar de não necessariamente dedicado às artes visuais com intenções museológicas ou curatoriais. Era a primeira de uma série de três mostras, sendo que as seguintes consistiram em um trabalho simulado e um trabalho voltado a um ambiente não institucional.

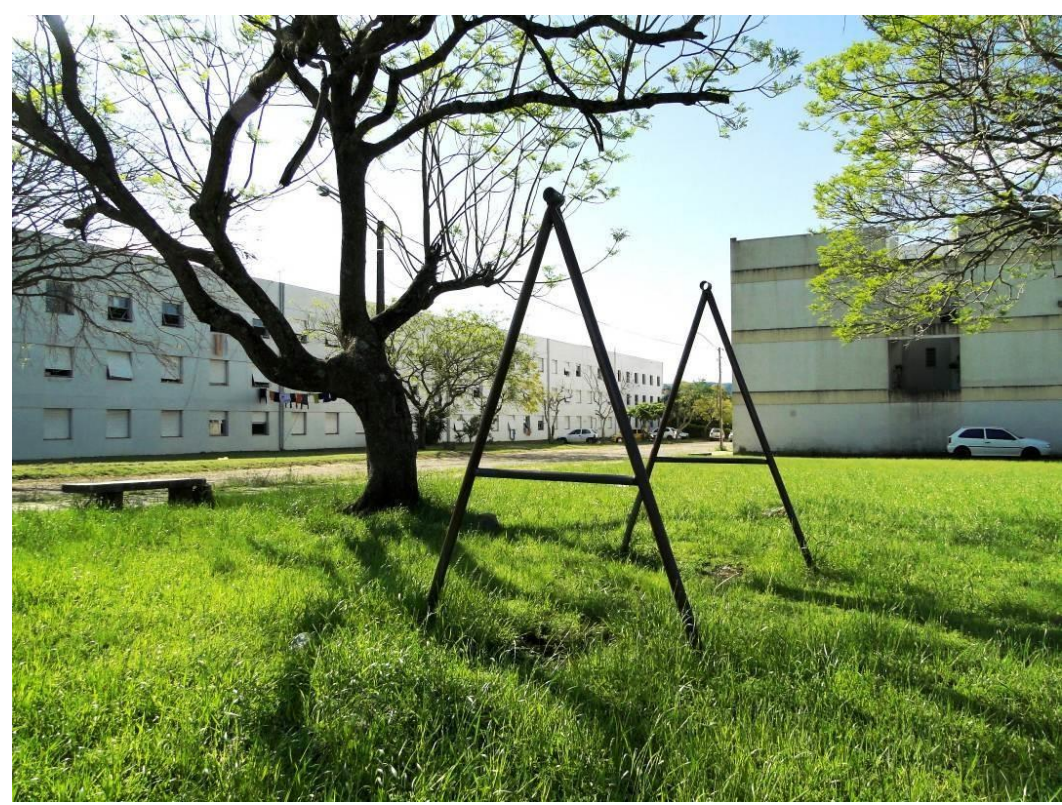

Figura.01: Estruturas de ferro escolhidas para a intervenção, no campus da UFSM

Uma das bases desta pesquisa é a linguagem da história em quadrinhos, que se vale, em grande parte de suas produções, de um diálogo entre imagem e texto, especialmente ao simular as falas dos personagens, entre outras formas, dentro de balões para eles apontados (EISNER, 1989). Mas mesmo sem a presença destes, é possível dizer, após cerca de um século de consolidação desta linguagem, que há um consenso em associarmos a palavra solta a uma figura que aparente a estar enunciando, seja através de uma expressão corporal ou facial ou do contexto em que se apresenta. A partir deste princípio, as letras " $A$ " do antigo balanço, mesmo sem estarem emolduradas por um balão de fala de qualquer natureza, poderiam se tornar as interjeições de uma narrativa, um desdobramento de minha pesquisa em que a escultura e o texto entrassem em diálogo.

\footnotetext{
${ }^{1}$ Mostra vinculada à disciplina "Ação e Reflexão no Contexto da Arte Contemporânea", com a Profa. Dra. Rebeca Stumm, foi chamada Exposição Paralela Mestrandos PPGART, por ocorrer concomitantemente a outros eventos no campus da UFSM, a feira Profitecs, a Jornada Acadêmica Integrada e a Jornada de Pesquisa e Formação do Centro de Artes e Letras. Na mesma disciplina foram realizadas também as exposições 5 Lugares e 11011011. Registros das três ocasiões podem ser encontrados no domínio virtual <5lugares.blogspot.com>.

Revista Digital do LAV - Santa Maria - ano VI, n.10, p. 98-112 - mar. 2013
}

ISSN 1983-7348 http://dx.doi.org/10.5902/198373487083 


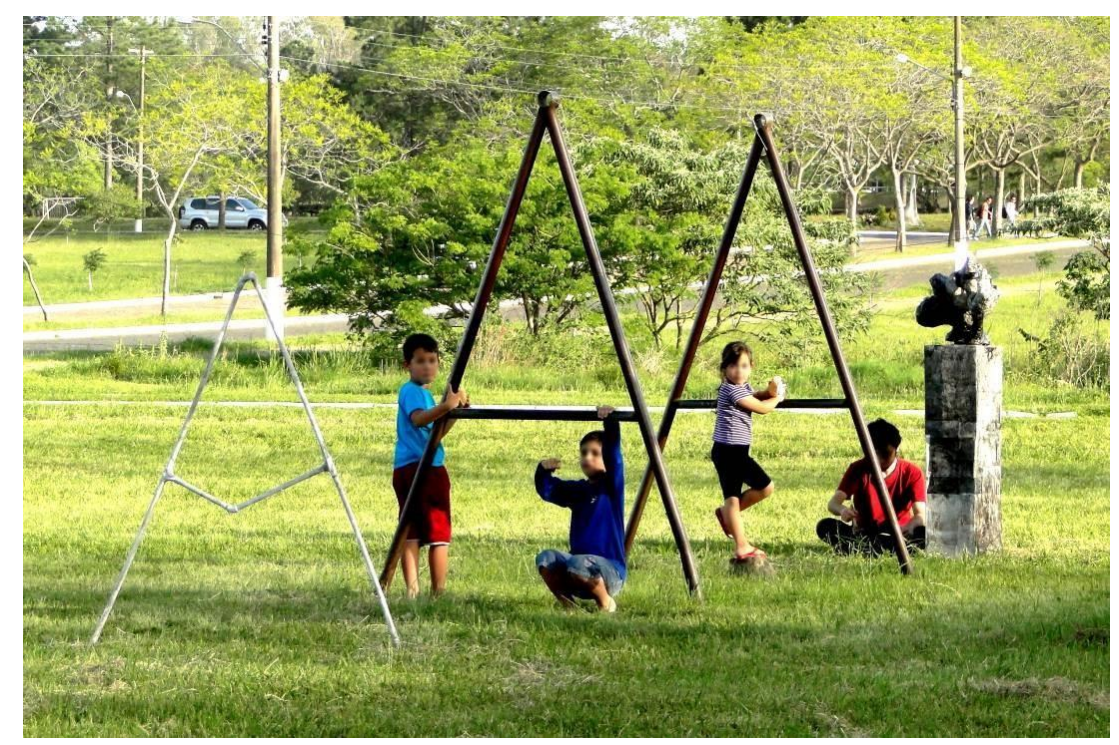

Figura.02: Escultura sendo instalada no espaço e crianças brincando nas letras

A primeira intervenção pensada para o local das letras " $A$ " havia sido um grito, de uma cabeça de grandes proporções que ficaria ao centro das letras, com duas mãos saindo do chão em torno delas. Uma situação de tensão que acabou por soar pouco apropriada, em virtude do movimento de trabalhadores da Universidade que por ali transitam com seus filhos, e do costume destes de se pendurarem nas letras, talvez nem tendo conhecido o balanço e a gangorra que ali há alguns anos ainda funcionavam.

Outras dificuldades para a realização de tal projeto eram a possível necessidade de uma letra "H" e uma exclamação junto aos "As" para uma aproximação a um ícone da linguagem dos quadrinhos, a interjeição "AAH!", e também o reduzido tempo que dispunha para confeccionar estes elementos em dimensões e estrutura satisfatórias. Considerando tais condições e as possíveis relações com o público envolvido, o humor presente numa cena de espirro teria uma leveza mais interessante e uma sutil crítica social poderia partir dali.

\section{Alguns referenciais poéticos}

Vistas de longe, as grandes cidades são um acúmulo de grandes edifícios, grandes populações e grandes áreas. Para mim, isto não é "real". O real é a cidade tal como ela é vista por seus habitantes. 0 verdadeiro retrato está nas frestas do chão e em torno dos menores pedaços de arquitetura, onde se faz a vida do dia-a-dia. (EISNER, 2009, p. 19)

A partir das palavras de Will Eisner, no prefácio de um clássico dos quadrinhos de sua autoria, Nova York: A Grande Cidade, cabe aqui abordar pesquisas artísticas que servem de subsídio a esta poética, e que têm em comum com ela uma associação da imagem com a cidade, e também com o humor e a narratividade. 
O uruguaio Gustavo Nakle (nascido em 1951) é conhecido desde os anos 1970 por ter se aventurado, em solo brasileiro, tanto em experiências na linguagem dos quadrinhos quanto em esculturas narrativas coloridas e caricaturais, em materiais como cerâmica, bronze pintado e "durecota, um composto de terracotas programadas para receber ferros e massa poliéster como suporte e estrutura" (ROLIM, 2011). Uma série que se destaca em sua produção é Os Quase Mitos Porto-Alegrenses, exposta na Agência de Leilões de Porto Alegre em dezembro de 2011, que consiste num conjunto de caricatos personagens do folclore urbano da capital do RS.
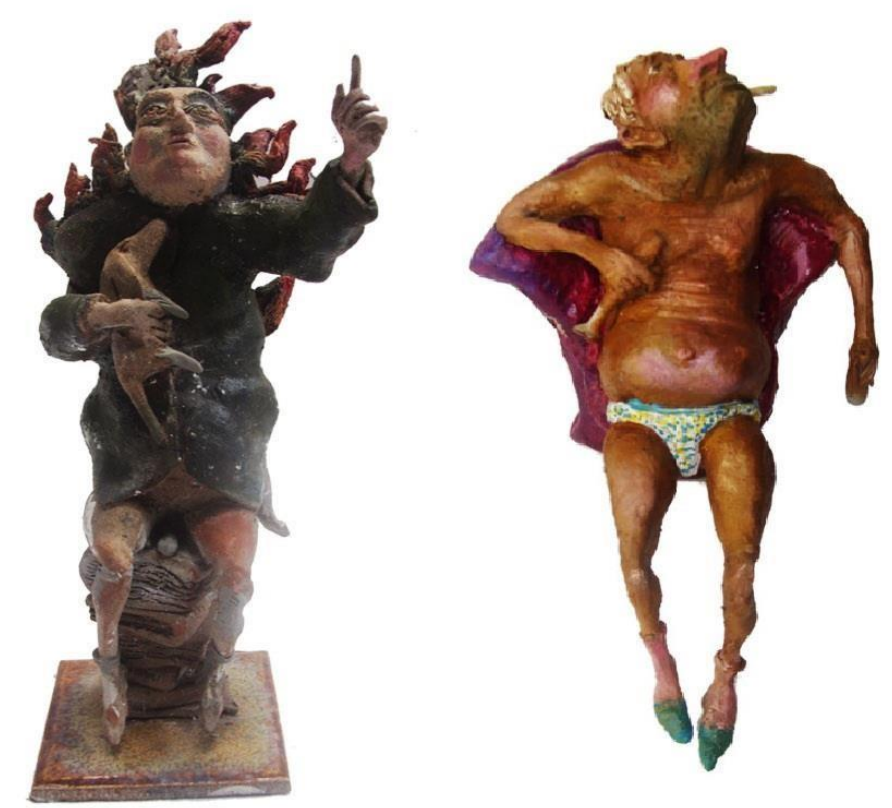

Figura.03: Gustavo Nakle, Literato do $10^{\circ}$ andar da Andrade Neves (esq.) e Bukowsky da Farrapos (dir.). Esculturas em durecota. Fonte: <www.nakleescultor.com.br $>$

Uma característica da maioria destas peças é ter como ambientação a referência presente em seu título a lugares da cidade, por exemplo o Exibicionista da Barão do Amazonas (única que o autor declara não ser fictícia), o Bukowsky da Farrapos, o Coelho hipnotizador da Tristeza, o Surfista arrependido do Lami, o Fantasma do banheiro público da Praça da Alfândega, a Adormecida da Lomba do Pinheiro, O literato do $10^{\circ}$ andar da Andrade Neves, os Comedores de ovos do Clube do Comércio, o Gnomo do Parque Farroupilha, entre outros.

É possível perceber neste trabalho sua fluência narrativa, seu humor cotidiano que proporciona uma identificação mesmo com quem não tem familiaridade com os bairros em questão. Através dos indícios presentes nessas esculturas se reconstitui toda uma história, talvez a adaptando às frestas do chão da própria cidade de origem do observador, ou por identificação com os personagens urbanos de seu contexto, dada sua expressão corporal, sua gestualidade de tipos humanos que são comuns à vivência na cidade. Acaba não sendo Revista Digital do LAV - Santa Maria - ano VI, n.10, p. 98-112 - mar. 2013 
mais tão importante se tais figuras são reais ou imaginadas, dada sua verossimilhança e personalidade. Ou, como dito por Paulo Gomes (2003, p.146), não é necessário discutirmos se uma obra de arte é fiç̧ão ou documentário, como se faria numa análise destinada aos campos do cinema e da literatura. "Na realidade, nunca se discute o estatuto de verdade desta obra. As obras de artes plásticas são. Pura e simplesmente são".

Um conceito com o qual procurei dialogar nessa inserção no espaço público, e que de certa forma considero também ter a ver com a produção de Nakle, é o de antimonumento. A partir deste podemos abordar diversas iniciativas de artistas que propuseram uma diluição do vínculo da arte pública com os valores reforçadores dos poderes hegemônicos que costumam financiar ou encomendar a confecção de bustos, estátuas equestres, placas em homenagem a heróis históricos, etc. Há até mesmo, entre os artistas do antimonumento, casos de rompimento com as estruturas e conformações estéticas comumente encontradas em exemplares desta categoria artística.

Para o pesquisador José Francisco Alves (2005, p.141), "O propósito do monumento seria o de trazer o passado para dentro do presente para inspirar o futuro. Assim, uma pergunta a ser feita é: O que escolheremos para comemorar nosso tempo?" O antimonumento surge, então, para contemplar a perda de lugar que tal lógica comemorativa começa a sofrer durante o século XX: "Tal oposição constitui-se, basicamente, no sentido de deslocar a forma e função do ato de comemorar" (p.141). A imponência monumental e a harmonia com a arquitetura podem ser pensadas de novas formas, uma situação heroica pode ser substituída por uma anti-heroica, um fato histórico por um cotidiano, questões morais e éticas podem ser problematizadas, e a narrativa não precisa seguir a linearidade que predominou até o modernismo.

Dirigir-se a um público e colaborar para sua transformação é hoje o principal objetivo da arte pública. Neste sentido o artista, em função do local da obra, tem que escolher e procurar atingir a audiência certa - quase sempre um público específico. Por isso, a obra deve responder fisicamente (esteticamente) ao local e psicologicamente (simbolicamente) em relação ao público do lugar. (ALVES, 2005, p.140)

Este antimonumento pode dialogar com um conceito mais ampliado de monumento, como o desenvolvido pelos filósofos franceses Deleuze e Guattari (1992, p.218):

É verdade que toda a obra de arte é um monumento, mas o monumento não é aqui o que comemora um passado, é um bloco de sensações presentes que só devem a si mesmas sua própria conservação, e dão ao acontecimento o composto que o celebra. 0 ato do monumento não é a memória, mas a fabulação. 
O passado trazido para o presente através do monumento não seria então a celebração de fatos ocorridos, mas sim algo que "transmite para o futuro as sensações persistentes que encarnam o acontecimento: o sofrimento sempre renovado dos homens, seu protesto recriado, sua luta sempre retomada" (DELEUZE; GUATTARI, 1992, p.229). Com isso toda forma de arte que deixe rastros ou registros pode ser considerada um tipo de monumento, uma fabulação que dialoga de diversas formas com os fluxos e movimentos daqueles que com ela convivem. Por isso não descrevo aqui nenhuma estátua pública como referencial poético deste processo artístico, apenas produções que coadunam com meus questionamentos, que dialogam em forma e tema com minhas propostas.

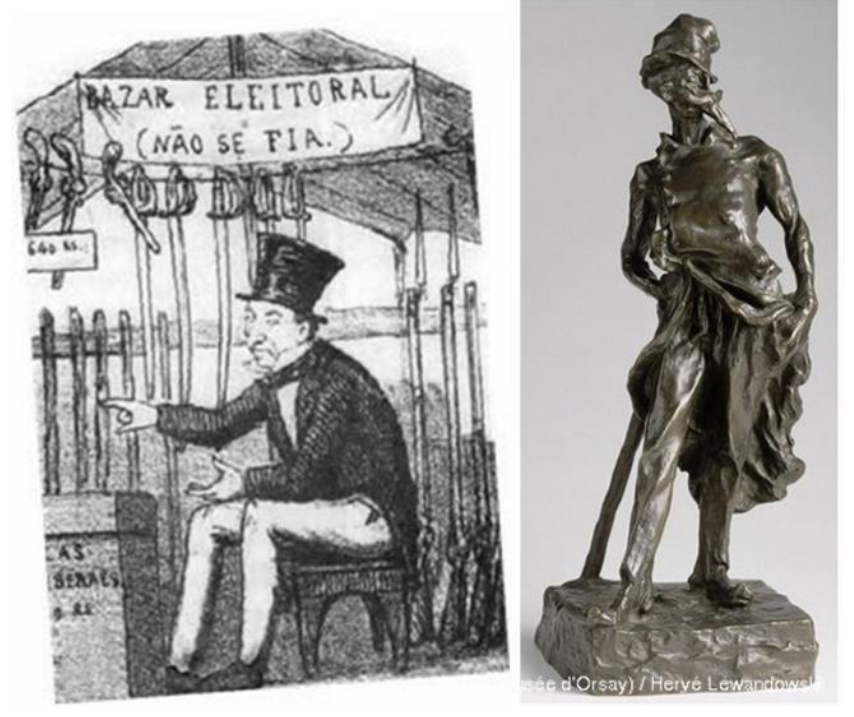

Figura.04: (Esq.) Angelo Agostini. Litografia da época do II Império. Fonte: $<$ www.revistafilosofia.com.br>.(Dir.) Honoré Daumier. Ratapoil. Escultura em bronze, cerca de 1851. Fonte: <www.musee-orsay.fr >

A figura do aristocrata de cartola que adotei como personagem para a intervenção A...A...A... pode ser considerada tanto uma referência às produções de Honoré Daumier (1808-1879) e Angelo Agostini (1843-1910) ${ }^{2}$ quanto uma paródia às políticas governamentais de incentivo à arte pública que há séculos vem financiando projetos de monumentos a "heróis nacionais" impostos por uma história parcial e excludente. Exemplos das sátiras destes artistas, que podem ser considerados embriões da linguagem dos quadrinhos, as imagens da Figura.04 narram as clássicas figuras do político negociador de votos e do militar decadente numa quixotesca tentativa de se impor.

Os mesmos valores aristocráticos constituem a temática que me motivou à criação dessa escultura: a presença da figura da "alta sociedade" em um momento de fragilidade, numa

\footnotetext{
${ }^{2}$ Daumier ficou conhecido por sua pintura denunciadora de desigualdades sociais, e por caricaturas escultóricas de homens públicos de sua época. Ele e Agostini publicavam, num formato semelhante ao que hoje chamamos charge, desenhos com legendas que tinham como tema uma crítica social de seus contextos, respectivamente França e Brasil.

Revista Digital do LAV - Santa Maria - ano VI, n.10, p. 98-112 - mar. 2013
}

ISSN 1983-7348 http://dx.doi.org/10.5902/198373487083 
expressão corporal que propositadamente difere da imponência e arrogância de grande parte dos bustos da estatuária pública. Ao contrário da formalidade e rigidez destes, há também a intromissão da mão do personagem, conduzindo o dedo indicador à região sob o nariz para lidar com seus espirros, escatologia sugerida através da boca escancarada e olhos fechados e pelas relações com a textualidade dos "As" de ferro e da placa do pedestal. O espirro nunca acontece, pois a escultura é estática. Fica somente, para quem se apropriar desta narratividade, a ânsia de que ele ocorra.

Consideremos os conceitos, presentes também em Alves (2005), de local como um simples ambiente de passagem e de lugar como um espaço que comporta conteúdo simbólico humano. O terreno em questão poderia se caracterizar, por exemplo, como um local para quem passa de ônibus por ali, e como um lugar para os moradores da casa que o frequentam em seus momentos de descanso e que provavelmente o dotam de diversas significações. Como possibilidade de ter certa harmonia com este ambiente de brincadeira e tranquilidade, propus um trabalho que lidasse com humor e de certa forma caracterizasse o espaço como um "logradouro público", uma "pracinha" onde os monumentos convivem com o trabalhador em seus momentos de descanso...

A comicidade dos aristocratas de cartola de Daumier e Agostini, e as possíveis associações destas narrativas com a contemporaneidade e com o próprio lugar da intervenção, constituíram a temática que me levou a sua criação. Parti inicialmente de uma aproximação formal proposital com os bustos institucionalizados através do pedestal, mas tendo sobre ele uma peça de compreensão formal mais difícil, uma figura caricata e disforme, quase ao nível do monstruoso. Devido a isto e a uma série de ruídos comunicacionais, a figura acabou, como muitos dos bustos que encontramos nas praças da própria cidade de Santa Maria, se perdendo na paisagem, sendo percebida apenas por quem convive mais demoradamente com o ambiente ou por olhos que por um motivo ou outro estejam ligeiramente mais atentos que os de um transeunte habitual. Ou seja, a percepção da própria presença deste antimonumento acabou sendo dificultada para quem tem este ambiente como um local e não como um lugar.

\section{Textura e Ruído}

Uma questão que se encontra presente em minha pesquisa em escultura, e que é marcante neste trabalho, é o limiar entre a riqueza de informação e o ruído. Experimentando figurações em torno da temática do grotesco em 2007, iniciei o desenvolvimento de um tipo de textura que aproveitava o gesto do modelado, o amassar de uma porção de argila sobre a outra. As deformidades resultantes proporcionavam ao trabalho uma força que acabava se apagando quando esta textura predominava, absorvendo a luz e tornando sua Revista Digital do LAV - Santa Maria - ano VI, n.10, p. 98-112 - mar. 2013 
fruição uma experiência ruidosa, confusa. O rumo que a pesquisa tomou foi a descoberta das "zonas de passagem", regiões em que uma hachura mais suave conduziria a luz de modo a valorizar a expressividade dos volumes. A partir dali a presença das texturas mais saturadas encontrou seu lugar através do contraste com aquelas mais lisas, que refletem a luz, proporcionando uma maior definição aos personagens presentes nos trabalhos, a exemplo da própria escultura de Daumier presente na Figura.04.

O "som branco", que é a mistura de todas as notas musicais, não informa nada, somente confunde. Segundo Umberto Eco (1976), é necessário acrescer ordem ao ruído para que este suscite alguma identificação. Um exemplo é a técnica de pavimentação conhecida como "macadame", de pedras de diversos formatos prensadas em disposição aleatória. Ela constitui um excesso de probabilidades, um ruído, pois é possível ver ali todo tipo de desenho, mas não há nenhuma intencionalidade nesse sentido.

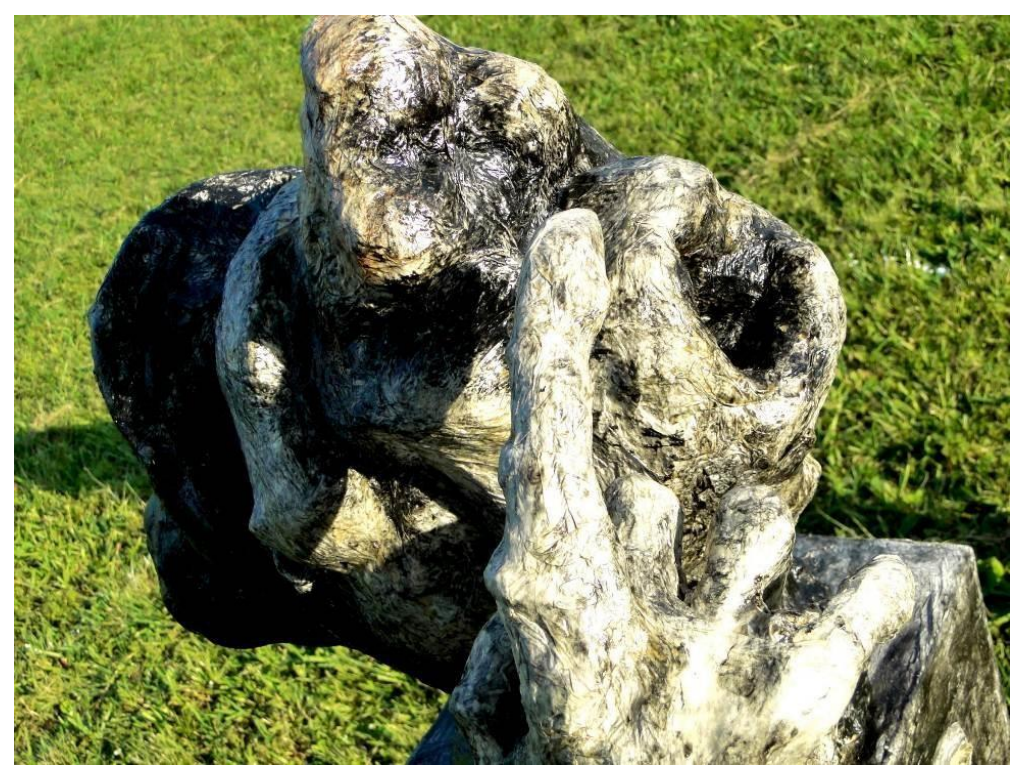

Figura.05: Detalhe da escultura $A . . . A . . . A \ldots$, no limite entre a valorização da textura e o ruído comunicacional

Ao descobrir as zonas de passagem, essa informação quantitativa, referente, segundo Eco (1976) à extração racional dos fatos comunicados, foi então valorizada em minha pesquisa, mas sem que fosse deixada de se levar em consideração a informação estética, a associação da primeira às possibilidades, proporcionadas pela obra, de surpresa intuitiva e prazer desinteressado. Creio ter conseguido, em alguns de meus trabalhos, utilizar o ruído como proposta, onde "o informal não é um abandono da forma como condição para comunicação, e sim seu uso como campo de possibilidades" (ECO, 1976, 
p.174). São construções que realizei em 2010, estruturadas em ferro e plástico e revestidas em papietagem ${ }^{3}$. Após estes, a maior parte das esculturas que fiz com técnicas semelhantes acaba também dialogando com essa questão, numa exploração dos limites entre o formalmente compreensível e o ruído.

Uma exploração dos limites entre o formalmente compreensível e o ruído se encontra na superfície proporcionada pelo material usado na escultura da intervenção $A$...A...A..., a rugosidade do papel colado, quase se aproximando da semelhança a uma pele enrugada ou queimada, assim como a calosidade das formas do arame e do papel torcido que se sobressaem. Tudo isto funcionou nesta peça como um ruído que indefine sua expressão. Ainda é buscado, nesse trabalho, um cuidado para que essa indefinição não se sobreponha à forma: é feita a tentativa de se criar a passagem de luz em contraste com as regiões texturadas, para que o campo de possibilidades de abertura de significado da obra não penda nem a torná-la uma comunicação unívoca, tampouco uma experiência meramente estética.

\section{Vivências do trabalho e a partir dele}

O busto da intervenção $A . . . A . . . A$... foi estruturado com ferro, garrafas de plástico e papel torcido, e revestido em papietagem. Por se tratar de um trabalho destinado a um espaço externo, passei nele, além da pátina com tintas guache e acrílica, uma camada de verniz. Construí seu pedestal com tubos de PVC revestidos por papel cartão e também por papietagem. Nele coloquei uma placa, uma folha impressa colada sobre papel cartão, com uma suposta homenagem, cheia de floreios e rodeios verbais, ao personagem inventado que nomeei Conde Barão Von Skhattaffoldzenenchintzler.

\footnotetext{
${ }^{3}$ Papietagem é uma técnica artesanal que estudei com o Prof. Ms. José Francisco Goulart no ateliê de Escultura do Centro de Artes e Letras-UFSM, e consiste na sobreposição de camadas de papel colado. No revestimento dos trabalhos em questão foi utilizado papel-toalha e cola confeccionada com polvilho e água.

Revista Digital do LAV - Santa Maria - ano VI, n.10, p. 98-112 - mar. 2013

ISSN 1983-7348 http://dx.doi.org/10.5902/198373487083 

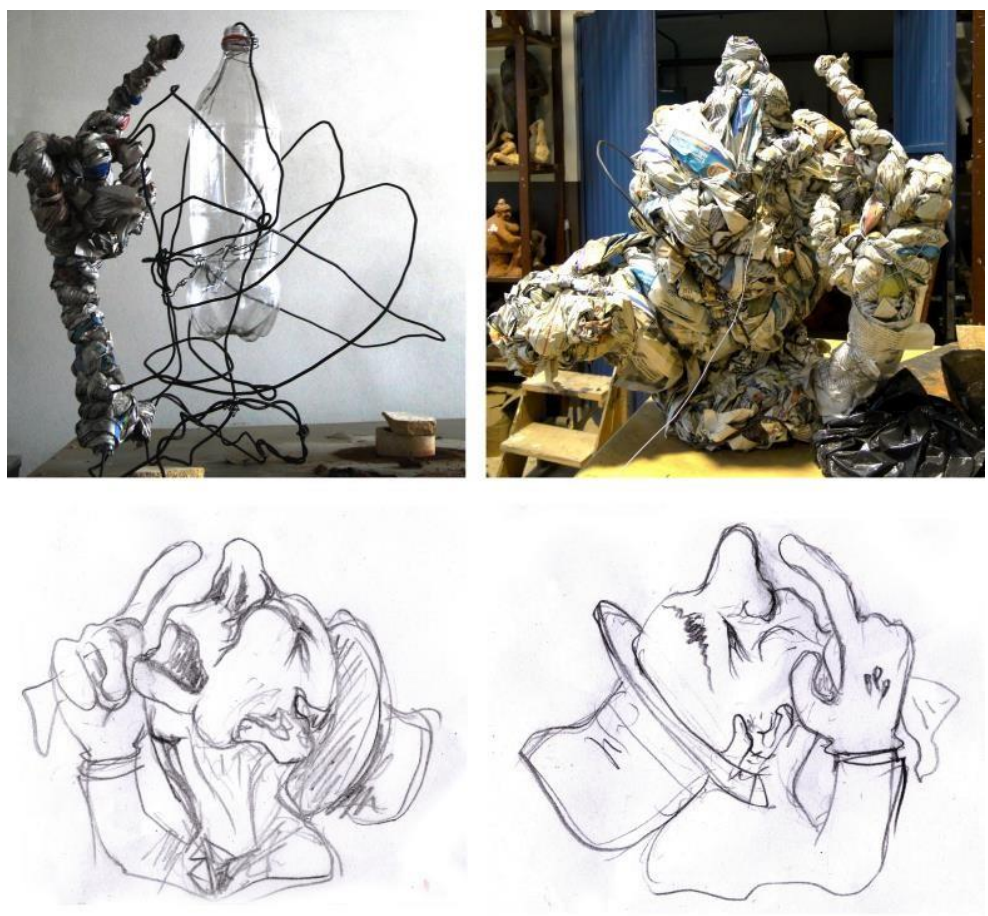

Figura.06: Etapas estruturais da confecção do busto e projetos em grafite sobre papel

Após finalizado e afixado o trabalho no lugar escolhido, espontaneamente, sem que fosse feito nenhum questionamento, fui abordado por algumas pessoas que o observavam a certa distância e que disseram tê-lo confundido com um material perene, até mesmo com uma fundição sobre um pedestal de cimento. Ao aproximar-se, tocar e sentir suas texturas, ouvir o som emitido sob leves impactos, ou mesmo a uma visualização mais atenta na distância da leitura da placa, era possível constatar que se tratava de uma peça feita basicamente de papel. Esta efemeridade de seu material, e também do tempo em que ela estaria exposta (uma semana), também se constituem como questionamentos dos monumentos perenes e sua presença imposta sobre um semnúmero de gerações por vir.

As crianças da vizinhança, acostumadas a brincar nas letras " $\mathrm{A}$ " maiores, a princípio me questionaram se era possível subir no " $A$ " pequeno, confeccionado com tubos de PVC revestidos com papietagem, e nesse momento minha presença, dando alguns retoques no trabalho, foi importante para esclarecer essas dúvidas e solicitar que brincassem somente nas estruturas, evitando danos precoces ao trabalho.

Durante os primeiros dias da intervenção, além dos já citados questionamentos que recebi sobre a materialidade do busto, percebi em mim mesmo uma atenção consideravelmente maior em relação àquele lugar. Obviamente por preocupação quanto à segurança do trabalho, cada vez que passava por ali percebia muito mais a presença dos jovens jogando futebol no campo próximo, das crianças que continuavam brincando nas estruturas. Acabei 
também tendo um contato maior com os moradores da casa, à medida que eles ficavam sabendo da autoria do trabalho e me abordavam para falar sobre ele, alguns até acrescentando novos detalhes à história inventada.

Na segunda metade da semana, um espetáculo contemporâneo roubou a cena: retroescavadeiras iniciaram uma obra de canalização do esgoto e pavimentação da via em frente aos prédios, que até então eram ligados por estradas de chão.

Quais são os monumentos da cidade contemporânea? Os equipamentos que a técnica de construção oferece exercem enorme atração na cidade: o espetáculo de uma grua ou bateestaca em funcionamento junta gente. A complexidade do equipamento, mesmo que não seja percebida sua função, é o bastante para o encantamento e garante uma atitude de contemplação. (RESENDE, 2006, p.359)

As atenções se voltaram completamente para o espetáculo urbano que ali se desenrolava. O lugar de brincadeira das crianças foi transferido para os montes de terra resultantes do processo. Meu trabalho foi esquecido. Mas, considerando o histórico de reivindicações há décadas sendo feitas pelos moradores da casa à administração da Universidade, esse esquecimento foi compensado pela possibilidade de melhoria na qualidade de vida do local.

A intervenção já havia cumprido seu papel no espaço tridimensional, podendo então ser retirada dali para passar a ocupar uma materialidade plana: a adaptação de fotografias suas à linguagem dos quadrinhos (Figura.07), procedimento que vinha adotando como regra dentro dessa pesquisa. Neste caso, elegi alguns dos registros fotográficos desta intervenção para serem utilizados eles mesmos como obra. Nesta experiência, creio que ao menos o viés comunicativo da proposta pode ser considerado melhor resolvido na narrativa plana do que na intervenção que a originou. Apesar disso não ficam nela explicitadas as vivências que o trabalho proporcionou tanto a mim quanto às outras pessoas que com ele tiveram contato. 

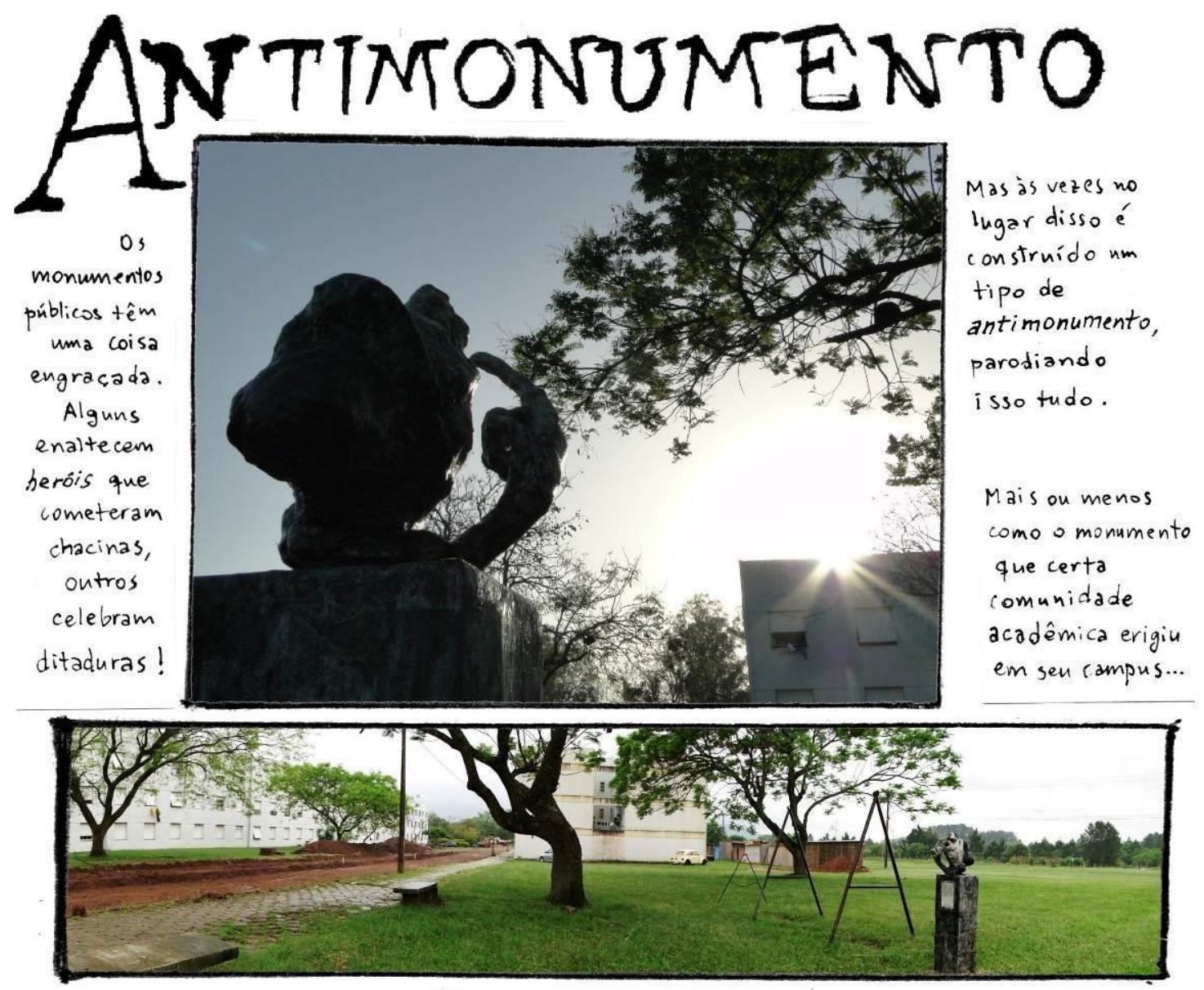

... Nada melhor que as duas letras $A$ de um balanso infantil esquecido para homenagear un ilustre momento envolvendo tais rogais: a inesquecivel visita do conde Barão von Skhattafoldzenenchintzler à sua querida instituiçáa de ensino.
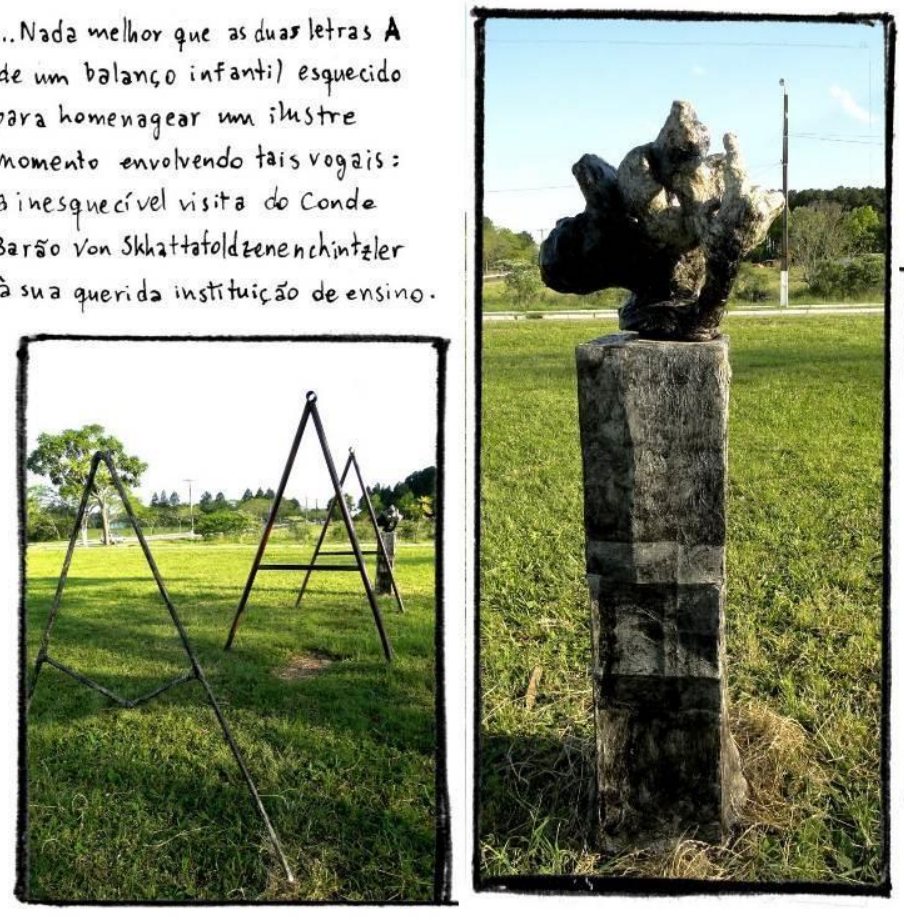
Sejam de concreto, bronze ou papel, os monumentos têm essa coisa engracada de refletir as desigualdades, as vezes de forma um tanto quanto cruel.

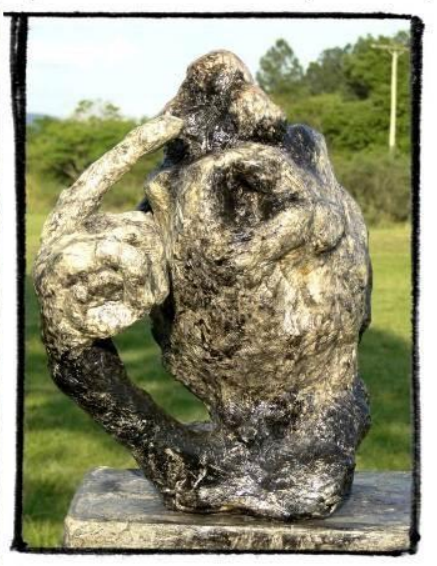

Até mesmo ao homenagear un ataque de espirros.

Figura.07: História em Quadrinhos Antimonumento. Diagramação a partir de fotografias digitais da instalação $A . . . A . . . A . . ., 2012$. 
A $\mathrm{HQ}$, por se constituir de uma única página, se aproxima ao conhecido formato quadrinístico da tira, apesar de contar com uma quantidade maior de texto que o comumente encontrado nesta modalidade. A narração em off ocorre num texto escrito a mão e digitalizado, colocado nos espaços entre os quadrinhos, sendo estes fotografias em que aos poucos vão sendo mostrados novos detalhes da escultura, no próprio espaço público onde ocorreu a intervenção. É uma narrativa curta, mas que se configura como um exercício de trânsito entre linguagens. Pode-se dizer, a partir daí, que o trabalho em um suporte de forma alguma vem a substituir o outro: os desdobramentos propostos somente se somam à pesquisa, a cada situação trazendo novas possibilidades de se trabalhar as relações buscadas entre a escultura e os quadrinhos.

\section{Considerações e encaminhamentos}

Assim, vejo nesta criação ficcional um diálogo entre o tridimensional e a $H Q$, entre a imagem figurativa e o texto, numa paródia que se assemelha em certos pontos às dos referenciais poéticos citados. Aos quase mitos de Gustavo Nakle, por lidar com as questões específicas de um contexto urbano, às charges de Angelo Agostini por satirizar a figura do aristocrata de cartola, à escultura de Honoré Daumier pelo ruído e pela iconoclastia. São todos antimonumentos onde o fato de se tratarem de ficção ou realidade pouco importa, são pesquisas em arte, feitas recentemente ou há mais de cem anos, em que valores são contestados, e com os quais me identifico, são indicações e inspirações de um caminho poético que sigo trilhando.

A associação dessa pesquisa com as questões de antimonumento rendeu a ela a possibilidade de ocupar o espaço tridimensional para além da publicação em página impressa. Experienciar e de certa forma mediar a interação do público com o trabalho foi um útil aprendizado tanto no que concerne a minhas práticas como propositor de ações artísticas quanto para meu exercício de docência. Nos meses seguintes meus encontros com a vizinhança foram permeados por perguntas da parte das crianças, se eu não iria fazer um balanço novo para elas. Vi-me obrigado a negar, pois o tempo de meu convívio com a casa do estudante era curto e já tinha decidido que meu foco de pesquisa durante ele seria a criação de narrativas em menores dimensões, sem o diálogo com o espaço público ou com as questões de monumentalidade. Tal diálogo passou a ser priorizado em minha atuação junto ao Coletivo (Des)Esperar. ${ }^{4}$

\footnotetext{
${ }^{4}$ Coletivo atuante desde 2009 em processos artísticos destinados a espaços públicos e cotidianos. Formado junto às artistas Tamiris Vaz, Francieli Garlet, Andressa Argenta e Florence Endres. Mais informações em <desesperar.blogspot.com>

Revista Digital do LAV - Santa Maria - ano VI, n.10, p. 98-112 - mar. 2013

ISSN 1983-7348 http://dx.doi.org/10.5902/198373487083 
A intervenção $A . . . A . . . A$... funcionou como um antimonumento no sentido de se instaurar em um espaço público e subverter algumas lógicas formais e ideológicas convencionadas na estatuária pública. Mas também exerceu o papel de monumento segundo Deleuze e Guattari, ao lidar com sensações e fluxos de um contexto específico, como a relação entre as crianças e o espaço do balanço, e a própria relação entre os estudantes e funcionários que por ali transitam cotidianamente e os valores evocados pela narratividade do trabalho.

Os diálogos com a linguagem da $H Q$, que tenho buscado em minhas produções tridimensionais, acabaram sendo mais evidentes no momento posterior a esta intervenção, a adaptação de seus registros fotográficos à página impressa. Tal procedimento passou a ser realizado, dentro de minha poética, em momentos diferentes dos processos, possibilitando obras em que a presença da escultura coexiste com a da página bidimensional de quadrinhos. Como minha humilde contribuição para o vasto campo de hibridações da arte contemporânea, as narrativas seguintes passaram, a partir do aprendizado com esta, a ser experimentadas segundo uma série de movimentos entre o tridimensional e o plano - mas isso já é outra história...

\section{Referências bibliográficas}

ALVES, José Francisco. Inventário da Escultura Pública de Porto Alegre. In: BULHÕES, Maria Amélia (org.). Memória em Caleidoscópio. Artes Visuais no Rio Grande do Sul.

Porto Alegre: Editora da UFRGS, 2005. Pp.135-170.

BIBE-LUYTEN, Sonia Maria. O que é História em Quadrinhos. Coleção Primeiros Passos. São Paulo: Brasiliense, 1985.

DELEUZE, Gilles; GuATTARI, Félix. O que é a filosofia? Trad. Bento Prado Jr. e Alberto Alonso Muñoz. Coleção TRANS. São Paulo: Editora 34, 1992.

ECO, Umberto. Obra Aberta. Trad. Sebastião Uchoa Leite. São Paulo: Perspectiva, 1976.

EISNER, Will. Nova York: A Grande Cidade. In: Nova York: A Vida na Grande Cidade. Trad. Augusto Pacheco Calil. São Paulo: Companhia Das Letras, 2009 Pp. 17-158.

EISNER, Will. Quadrinhos e Arte Sequencial. Trad. Luís Carlos Borges. São Paulo: Martins Fontes, 1989. 
GOMES, Paulo César Ribeiro. Comentários: Alterações e derivas da narrativa numa poética visual. 2003. 316f. Tese (Doutorado em Artes Visuais) - Instituto de Artes, Universidade Federal do Rio Grande do Sul. Porto Alegre, 2003.

RESENDE, José. Ausência da Escultura. In: FERREIRA, Glória; COTRIM, Cecília (orgs.). Escritos de Artistas: Anos 60/70. Rio de Janeiro: Jorge Zahar Editores, 2006.

\section{Documentos Eletrônicos}

Honoré Daumier: Ratapoil. In: Musée D’Orsay. Disponível em:

$<$ www. museeorsay.fr/index.php?id $=851 \& \mathrm{~L}=1 \& \mathrm{tx}$ commentaire pi $1 \% 5$ BshowUid $\% 5 \mathrm{D}=20$

717\&no cach e=1>. Acesso em: 06 nov. 2011.

Nakle Escultor. Disponível em: <www.nakleescultor.com.br>. Acesso em: 16 abr.2011.

ROLIM, Michele. A cidade mitológica de Gustavo Nakle. In: Jornal do Comércio, edição de 01 dez.2011. Disponível em <jcrs.uol.com.br/site/noticia.php?codn=80128> , acesso em 02 mar.2012.

VILELA, Ney. Política no Segundo Império (1840-1889): a calma dos cemitérios. In: Portal Ciência e Vida. Disponível em:

<www.revistafilosofia.com.br/eslh/edicoes/8/imprime78832.asp >. Acesso em: 06 nov. 2011.

Fábio Purper Machado (UFSM)

Paulo Gomes (UFRGS)

Recebido em: $31 / 10 / 2012$

Aprovado em: 18/01/2013 